\title{
AIDS e as primeiras respostas voltadas para a epidemia: contribuições dos profissionais de saúde
}

\author{
AIDS and early responses to the epidemic: contributions from health professionals \\ SIDA y las primeras respuestas ante la epidemia: contribuciones de los profesionales de salud
}

\author{
Isabel Cristina Alves Maliska'; Maria Itayra Coelho de Souza Padilha ${ }^{\text {II }}$ Selma Regina Andrade ${ }^{I I I}$
}

\begin{abstract}
RESUMO: Estudo descritivo qualitativo com perspectiva socio-histórica, que objetivou descrever o contexto em que surgiram as primeiras ações em resposta à epidemia da Síndrome da Imunodeficiência Adquirida (AIDS) em Florianópolis-SC, Brasil. O marco histórico inicial é o ano de 1986, quando o primeiro caso da doença foi notificado, até 1993, quando foi oficializado o Programa Municipal de Doenças Sexualmente Transmissíveis (DST)/AIDS no município. Utilizou-se como referencial teórico-metodológico a nova história, mediante a pesquisa documental e história oral temática. Os sujeitos do estudo foram seis profissionais de saúde que exerceram atividades de assistência e/ou gestão vinculadas às DST/AIDS, no período do estudo. Para tratamento dos dados, utilizamos análise de conteúdo. Destacaram-se, neste estudo, a falta de estrutura do sistema de saúde na época e as iniciativas pessoais de profissionais de saúde que entenderam a emergência da epidemia e passaram a articular ações assistenciais e preventivas, apesar dos poucos recursos disponíveis na época.
\end{abstract}

Palavras-Chave: Síndrome da Imunodeficiência Adquirida; Sistema Único de Saúde; sistemas locais de saúde; história.

ABSTRACT: This socio-historical, descriptive, qualitative study describes the context in which early action arose in response to the AIDS epidemic in Florianópolis. The study timeframe is from 1986, when the first AIDS case was reported, to 1993 , when the Municipal Program on Sexually Transmitted Diseases (STDs)/AIDS was officially launched in the city. The theoreti$\mathrm{cal}$ and methodological frame of reference given by 'new history' informed documentary research and thematic oral history. The study subjects were six health professionals engaged in STD/AIDS-related care and/or management activities during the study period. Data were processed using content analysis. The study highlighted the inadequate structure of the health system at the time and personal initiatives by health professionals who understood the emergency nature of the epidemic and began to organize care and preventive measures, despite the sparse resources available at the time.

Keywords: Acquired Immunodeficiency Syndrome, Unified Health System, local health systems, history.

RESUMEN: Estudio descriptivo cualitativo con perspectiva socio y histórica, cuyo objetivo fue describir el contexto en que surgieron las primeras acciones en respuesta a la epidemia del SIDA en Florianópolis-SC-Brasil. El marco inicial es el año 1986, cuando se reportó el primer caso de la enfermedad, hasta 1993, cuando fue oficializado el Programa Municipal de Enfermedades de Transmisión Sexual (ETS) / SIDA en la ciudad. Fue utilizado la nueva historia, mediante la investigación documental y la historia oral temática. Los sujetos de estudio fueron seis profesionales de salud que ejercían actividades de atención y/o gestión vinculadas al ETS-SIDA durante el período en estudio. Para el procesamiento de los datos, se utilizó el análisis de contenido. Se destacan, en este estudio, la falta de estructura del sistema de salud en ese momento y las iniciativas personales de profesionales de la salud que comprenden la aparición de la epidemia y empezó a articular acciones y la atención preventiva, a pesar de los limitados recursos disponibles en ese momento.

Palabras Clave: Síndrome de Inmunodeficiencia Adquirida; Sistema Único de Salud; sistemas locales de salud; historia.

\section{INTRODUÇÃO}

A epidemia da Síndrome de Imunodeficiencia Adquirida, amplamente reconhecida pela sigla AIDS, por sua complexidade e influência em diversos aspectos da vida social, apresenta contornos particulares em cada contexto no qual se dissemina. Nesse sentido, para apreender a dinâmica da doença, se faz necessário compreender o histórico e o desenvolvimento da epidemia em distintos contextos ${ }^{1}$.

No Brasil, o surgimento da AIDS coincidiu com o enfrentamento de uma grave crise social, política e econômica. O momento histórico em que a AIDS adentrou no país caracterizou-se também pela instau-

IEnfermeira Assistencial do Hospital Universitário da Universidade Federal de Santa Catarina. Doutora em Enfermagem pelo Programa de Pós-Graduação em Enfermagem da Universidade Federal de Santa Catarina. Membro do Grupo de Estudos da Historia do Conhecimento da Enfermagem e Saúde. Florianópolis, Santa Catarina, Brasil.E-mail: isabel.alves07@yahoo.com.br.

IIEnfermeira, Professora Associada do Departamento de Enfermagem da Universidade Federal de Santa Catarina. Doutora em Enfermagem pela Escola Anna Nery da Universidade Federal do Rio de Janeiro. Líder do Grupo de Estudos da Historia do Conhecimento da Enfermagem e Saúde. Rio de Janeiro, Brasil.E-mail: padilha@ccs.ufsc.br

IIEnfermeira, Doutora em Enfermagem, Professora Adjunta do Departamento de Enfermagem da Universidade Federal de Santa Catarina. Florianópolis, Santa Catarina, Brasil. E-mail: selma@ccs.ufsc.br 
ração progressiva do regime democrático brasileiro e pelo surgimento e reorganização de diversos movimentos sociais ${ }^{2,3}$.

A partir dos primeiros casos de AIDS no país, foram articuladas as primeiras respostas políticas a epidemia, a exemplo de um programa inicial de mobilização foi estabelecido no estado de São Paulo, no ano de 1983. A descentralização do aparelho estatal no Brasil foi fundamental para uma resposta relativamente precoce e eficaz no combate a epidemia, visto que as primeiras respostas governamentais ocorreram nos próprios estados afetados pela epidemia ${ }^{4}$.

Em Santa Catarina, a primeira notificação de AIDS ocorreu no ano de 1984, no município de Chapecó. Embora não tenha sido notificado nenhum caso em 1985, no ano de 1986 foram notificados nove casos no estado e dentre estes, três casos no município de Florianópolis ${ }^{5}$. Desde então, a disseminação progressiva de casos de AIDS em algumas cidades catarinenses passou a se destacar no cenário nacional, chamando a atenção das autoridades em saúde ${ }^{6}$.

No fim da década de 1980, algumas ações voltadas para o controle da AIDS foram sendo estruturadas, com a implantação de campanhas educacionais vinculadas na mídia, especialmente a televisiva, o início da cooperação entre os serviços federais, estaduais e locais em relação à AIDS, além da implantação de políticas de controle do sangue no Brasil. A partir da década de 1990, um período de recessão profunda se fez no país, marcado por uma política neoliberal e pela deterioração dos serviços sociais. Nesse contexto, o Programa Nacional de AIDS sofreu uma redução de pessoal e orçamentária, com prejuízo para ações de vigilância epidemiológica e de prevenção, resultando em uma crise que se estendeu até o final de 1992. Desse modo, chegou-se em 1993 ao registro de 37.039 casos de AIDS no país, representando o maior número de casos na América Latina, e um dos países com maior número de casos notificados no mundo?

Com esta síntese histórica, interessa-nos aqui tratar da primeira fase da epidemia de AIDS no Brasil, anterior ao convênio firmado junto ao Banco Mundial em 1993, que passou a fomentar grande parte das políticas de combate a epidemia no país. Trata-se de um período marcado pelo crescente número de casos da doença, com alta morbidade e mortalidade, vinculada a um alto preconceito e estigma. Partindo deste contexto, elegemos como foco deste estudo o município de Florianópolis - Santa Catarina, que teve notificado o primeiro caso de AIDS em 1986, e até o ano de 1993 teve 488 casos de AIDS notificados na cidade, sendo o uso de drogas injetáveis o principal modo de transmissão $(56,3 \%)$, seguido da transmissão heterossexual (22\%), homossexual (14,5\%), bissexual $(6 \%)$ e vertical $(4,1 \%)^{8}$.

A partir do primeiro caso de AIDS notificado no município, algumas ações foram instauradas no sentido de conter a epidemia, contando especialmente com esforços de profissionais de saúde e sociedade civil, além das esferas governamentais do estado e município. Desse modo, este estudo teve por objetivo descrever o contexto em que surgiram as primeiras ações em resposta à epidemia da AIDS em Florianópolis, buscando evidenciar a contribuição da enfermagem para a construção da política de controle da epidemia nesta realidade local.

\section{Referencial Teórico-Metodológico}

Trata-se de um estudo de natureza socio-histórica, que utilizou as bases filosóficas da nova história. A nova história faz parte de um movimento de oposição à história tradicional e positivista do século XIX. A nova história é uma história problemática, explicativa, que trata das evoluções e das transformações, que busca compreender o presente pelo passado e o passado pelo presente ${ }^{9}$. Esta perspectiva histórica tem valorizado a análise qualitativa e a importância das experiências individuais, abrindo espaço para o estudo do presente, do político, da cultura, e reincorporando o papel do indivíduo no processo social, estimulando o uso das fontes orais.

O contexto do estudo foi a Secretaria Municipal de Saúde de Florianópolis, sendo os sujeitos pesquisados, profissionais que atuaram direta ou indiretamente no Programa DST/AIDS Municipal e/ou suas unidades assistenciais.

Para coleta dos dados, foram utilizadas fontes documentais primárias e secundárias, bem como fontes orais. Quanto às fontes orais, realizamos entrevistas pela técnica da História Oral Temática. A História Oral Temática é um método de pesquisa que privilegia a realização de entrevistas com pessoas que participaram ou testemunharam acontecimentos, sendo esta uma forma de aproximação do objeto de estudo ${ }^{10}$. Foram entrevistados seis profissionais de saúde, sendo eles as três primeiras enfermeiras e três primeiros médicos que exerceram atividades de assistência e/ou gestão vinculadas às DST/AIDS em Florianópolis no período do estudo. Nos depoimentos, os sujeitos estão identificados como E1, E2 e E3 para a categoria enfermeiro, e como M1, M2 e M3 para a categoria médico. Para tratamento dos dados, utilizou-se análise de conteúdo ${ }^{11}$, onde foram classificadas as unidades de análise previamente selecionadas (palavras-chave), com agrupamento das semelhanças, constituição de subcategorias e seu reagrupamento para identificação das categorias. A análise dos relatos orais foi sustentada também por informações obtidas nos documentos primários e secundários, tendo como referencial de análise a Política Nacional de Saúde, especialmente dos conceitos de universalidade, integralidade e descentralização, conhecidos como princípios doutrinários e organizacionais do Sistema 
Único de Saúde (SUS). Este estudo foi aprovado pelo Comitê de Ética em Pesquisa com Seres Humanos da Universidade Federal de Santa Catarina, sob o no 592 315996/2010. Foram observados todos os princípios éticos de pesquisa, em todas as fases do estudo.

O recorte histórico se deu a partir de 1986, ano que o primeiro caso de AIDS foi notificado em Florianópolis, até 1993, quando se inicia a estruturação do Programa DST/AIDS do município. Para tratamento dos dados, utilizou-se análise de conteúdo ${ }^{11}$, chegando a duas categorias: Os primeiros casos atendidos no Hospital Nereu Ramos (HNR); e A estruturação do serviço municipal de saúde para o atendimento dos casos de AIDS.

\section{Resultados E Discussão}

\section{Os primeiros casos atendidos no Hospital Nereu Ramos}

As primeiras ações voltadas a AIDS concentraram-se institucionalmente no HNR, referência no Estado de Santa Catarina em doenças infectocontagiosas, vinculado ao serviço de saúde estadual, localizado em Florianópolis. O primeiro caso de AIDS atendido nessa instituição ocorreu em 1985, causando grande repercussão:

$\mathrm{Na}$ verdade eu não sei se esse caso apareceu nas estatísticas [em 1985], era uma pessoa muito conhecida daqui, e ele tinha uma influência social, ele estava internado no [Hospital de] Caridade, de uma pneumonia que não resolvia, e veio para o Nereu e na época ficou muito velado o caso, e ele logo foi a óbito, e ele seria notificado pelo critério de óbito e provavelmente não foi. (E1)

Era muito complicado, porque cada caso de AIDS notificado era uma manchete de jornal, era tudo escondido. [...] Naquela época era complicadíssimo, imagina você atender uma autoridade com AIDS, ou um religioso com AIDS. (M2)

Nos depoimentos apresentados, são destacados por estes profissionais questões ligadas ao preconceito e ao estigma ao doente de AIDS, que repercutiam diretamente na assistência, ao ter que se lidar com a pressão da mídia, evitar a exposição do indivíduo e de sua vida, especialmente por alguns doentes terem posição de notoriedade na sociedade local. A partir do primeiro caso de AIDS no Estado esta instituição passou a estruturar-se para assistência, reservando, no ano de 1985, quatro leitos para isolamento e tratamento destes pacientes. Estes se tornaram insuficientes devido à demanda que passou a ser encaminhada de várias partes do estado ${ }^{12}$. Em 1987, foi iniciado o atendimento ambulatorial no HNR dedicado a pacientes com AIDS, formando-se nesta época uma equipe multidisciplinar composta por assistente social, enfermeira, médico, odontólogo e psicólogo ${ }^{13}$ :
Nós nos reunimos e criamos o primeiro ambulatório e a [...] enfermeira que fazia a admissão, que fazia a pré-consulta, a pós-consulta e isso daqui começou a crescer e a gente vinha aqui todas as manhãs, as manhãs inteiras [...] As pessoas vinham aqui enlouquecidas. Então todo mundo que tinha suspeita, ansiedade, riscos, vinha para cá, não tinha jeito, HIV [Vírus da Imunodeficiência Humana, originada do inglês: $\mathrm{Hu}$ man Immunodeficiency Virus] era no Hospital Nereu Ramos, eram filas inteiras. (M3)

O ambulatório deste hospital passou a ser uma importante referência para a população que, assustada com a chegada da epidemia, procurava esta instituição para orientação, diagnóstico e assistência dos casos confirmados, o que necessitou em uma melhor estruturação do serviço para atender esta demanda. No decorrer da década de 1990 outros serviços voltados a AIDS foram implantados no HNR, como o serviço hospital-dia, criado em 1992 e credenciado pelo Ministério da Saúde em 1995, através da Portaria № $70 / 95^{12,14,15}$.

Nessa época, eram muitas as demandas dos pacientes portadores de HIV/AIDS e familiares, visto que a AIDS de fato havia chegado na cidade, mas o serviço de saúde ainda estava em processo de estruturação e os profissionais do HNR também percebiam a necessidade de se instrumentalizar tecnicamente para o atendimento destes casos, pois a doença, por seu alto grau de letalidade, exigia respostas urgentes. Neste sentido, apesar de todo o esforço dos profissionais de saúde que estavam comprometidos com a epidemia, era necessário também o envolvimento da sociedade civil para que a luta contra a epidemia tivesse mais força e maior visibilidade social, frente às necessidades que as pessoas acometidas pela doença apresentavam:

Naquela época, basicamente, éramos dois médicos do Hospital Nereu Ramos e eu, na questão institucional. E, ao mesmo tempo, nós e mais alguns voluntários começamos a nos reunir, em 1987, dentro do Hospital Nereu Ramos, junto com Assistentes Sociais, Enfermeiras. Eu me lembro de algumas pessoas do Hospital Nereu Ramos que foram importantíssimas na criação do GAPA [Grupo de Apoio à Prevenção da AIDS] e que fizeram como eu, elas trabalhavam numa ONG [Organização não governamental] o GAPA, e dentro do Hospital Nereu Ramos. Então foi em 87 que criamos $o$ GAPA. (M1)

Foi dessa forma que foi articulada a primeira organização não-governamental voltada para a AIDS em Florianópolis, em 06 de agosto de 1987, criada nas dependências do Hospital Nereu Ramos, formada por profissionais de saúde (médicos, enfermeiras, outros profissionais da enfermagem, assistentes sociais) e voluntários ${ }^{16}$. A iniciativa de criar o GAPA, em Florianópolis, foi influenciada por um movimento que se estendia por todo o país, cujo objetivo era apoiar 
o doente de AIDS face à rejeição social pela qual era submetido, bem como exigir das autoridades em saúde uma melhor estrutura de atendimento a estes doentes, como leitos hospitalares e tratamentos que se dispunham na época:

Era muita gente, muito problema e já se criava ONGs no mundo inteiro, nos Estados Unidos, no Brasil, no Rio, em São Paulo, então resolveu se criar o GAPA [...] para dar apoio a essas pessoas que não tinham onde buscar apoio, porque era muito difícil ser soropositivo. [...] Era até paradoxal, porque a gente estava aqui no hospital, mas a própria ONG que nós criamos era para brigar com o próprio hospital para fornecer melhores condições para os pacientes, só que não dependia da gente, se fazia o que podia. (M2)

Praticamente em todos os países do mundo foram criadas organizações não-governamentais voltadas a epidemia. As primeiras a serem criadas dedicaramse especialmente a questões específicas de cuidado, apoio, informação e educação sobre a doença, dando origem a um movimento mundial, que de diversas formas buscou desestigmatizar a $\operatorname{AIDS}^{17}$.

Além da criação do GAPA, foi criado em $1^{\circ}$ de dezembro de 1991 a Fundação Açoriana para o Controle da AIDS (FAÇA), segunda organização não governamental voltada para a AIDS do município de Florianópolis, também nascida no Hospital Nereu Ramos, com a participação de profissionais de saúde e voluntários, porém com uma linha de atuação direcionada para o desenvolvimento de ações para prevenção do HIV e AIDS, visando fortalecer o papel político de homens e mulheres no exercício da cidadania ${ }^{17}$.

\section{A estruturação do serviço municipal de saúde} para o atendimento dos casos de AIDS

No serviço municipal de saúde de Florianópolis, as primeiras mobilizações acerca da epidemia da AIDS partiram de iniciativas pessoais e pontuais, a exemplo de um médico que vinha acompanhando o movimento da epidemia e passou a realizar um trabalho preventivo na mídia e nas escolas, procurando esclarecer do que se tratava esta doença:

Nos anos 80, não havia dezenas de pessoas trabalhando $e,[\ldots]$ quem sabia alguma coisa ia fazendo ou o que convinha fazer [...] porque no inicio era evitar que a epidemia chegasse de maneira forte e ter instrumentos para controlar a epidemia [...] Depois, passado alguns anos viu-se que a coisa chegou realmente e que seria necessário continuar o trabalho preventivo na mídia, nas escolas, usando todos os instrumentos que se tinha e também já começar a clinicar. (M1)

Este profissional acabou se tornando uma referência em AIDS no município, em um momento que não havia qualquer serviço ou programa estruturado na Secretaria Municipal de Saúde de Florianópolis voltado para essa epidemia. Até a formação do ambulatório de DST, no ano de 1989, as atividades desenvolvidas no âmbito da Secretaria Municipal de Saúde de Florianópolis eram pontuais, voltadas para a prevenção e esclarecimento da população, visto que no decorrer da década de 1980 as notícias veiculadas na mídia eram pouco esclarecedoras, trazendo contradições e refletindo a perturbação causada pela epidemia no próprio campo científico ${ }^{18}$ :

Tinha-se que esclarecer, informar a população e informar com realismo, porque tinha muita mitificação, muita coisa que nós tínhamos que lutar contra. [...] No primeiro ano, em 87 eu registrei: foram 63 palestras, a gente chamava de palestras, mas na realidade eram informações, a pedido de escolas municipais e estaduais do município. [...] Eu me lembro que tinha um caso de AIDS em um bairro, que a comunidade solicitou uma reunião conosco e nós fizemos a reunião dentro de uma escola, que não coube todo mundo; as pessoas estavam do lado de fora e nas janelas ouvindo o que a gente tinha a dizer. (M1)

A AIDS foi amplamente reconhecida por sua capacidade de produzir discussões que envolviam muito mais do que aspectos patológicos, contribuindo para ampliar o olhar de muitos profissionais de saúde sobre o processo saúde-doença. Esse período inicial da epidemia foi determinado por um pânico moral, em que principalmente, ao longo da década de 1980, toda atenção se dirigia para o comportamento individual, tanto para expandir quanto para controlar a infecção do HIV. Neste contexto, a doença era mais tratada como contagiosa do que infecciosa ${ }^{19}$.

No que diz respeito às ações assistenciais, o serviço municipal de saúde nessa época passava por um período de reestruturação, devido às transformações do serviço de saúde brasileiro ocorridas no fim da década de 1980, para implantação do SUS. Nesse processo, gradativamente, alguns serviços de saúde deixavam de ser de responsabilidade do estado para serem assumidos pelo município, a exemplo das unidades sanitárias do conhecido Departamento de Saúde Pública:

A Secretaria Estadual de Saúde era a proprietária e administradora do Departamento de Saúde Pública. Ali sempre foi uma instituição estadual, ali tinha uma porção de serviços [...] havia também um serviço de doença sexualmente transmissível [...] Então era um ambiente em que sabíamos que muitas prostitutas iam, [...] então tinha um serviço de doenças venéreas que era um precursor de doenças sexualmente transmissiveis. (M3)

O Departamento de Saúde Pública, conhecido como DSP ou DASP, era uma estrutura estadual que oferecia diversos serviços de saúde, referência para todos os municípios da região, tendo sido municipalizado em 1990. Embora esse serviço atendesse historicamente casos de DST, não havia uma denominação oficial de ambulatório de DST. Esta denominação surgiu a 
partir de 1989, quando um médico e uma enfermeira foram destinados para o atendimento exclusivo dessa demanda, que era significativa. Esse serviço passou a ser gradativamente procurado por pessoas buscando orientações, diagnóstico ou tratamento para o HIV, pois sendo a AIDS uma doença sexualmente transmissível, seria natural que o atendimento fosse a ele agregado:

Então quando começou a aparecer os casos de AIDS a gente teve que começar a se estruturar para atender uma coisa que nem sabia direito como é que era, era tudo muito novo. Então foi uma coisa gradativa, ela foi se integrando ao serviço e a gente foi aprendendo com a infecção, com a doença, com os casos que apareciam todos os dias [...] aquelas pessoas que se sentiam mais vulneráveis eram as que vinham mais, os homossexuais, os usuários de drogas, as prostitutas. (E2)

Além de todo estigma sofrido pelo indivíduo portador da síndrome, a falta de perspectiva da doença se evidenciava especialmente no momento de revelar o diagnóstico da soropositividade para o HIV, pois o sentimento de impotência era inevitável frente a consciência da incapacidade de tratar a doença, visto que não havia tratamento no sistema público de saúde que pudesse restaurar o sistema imunológico do indivíduo infectado pelo $\mathrm{HIV}^{18}$ :

Na época em que eu comecei, quando tu entregavas um resultado positivo para alguém tu não tinhas muito o que oferecer. A gente tinha que lidar muito mais com o emocional das pessoas, porque a gente não tinha o que tu tens hoje em dia, essa gama de medicamentos, todos os exames, monitorar a infecção para saber o momento certo de entrar com o medicamento. (E3)

A década de 1980 foi marcada por uma alta mortalidade por AIDS, devido a falta de tratamento que pudesse controlar a doença. A zidovudina (AZT) começou a ser utilizada nos Estados Unidos em 1987, tendo bons resultados como bloqueador da replicação viral ${ }^{20}$, sendo disponibilizado no Brasil na rede pública de saúde a partir do ano de $1991^{21}$. Antes do AZT, a sobrevida não passava de seis meses e só se podia garantir o tratamento de doenças oportunistas, decorrentes da infecção pelo $\mathrm{HIV}^{22}$. Frente a este cenário, o diagnóstico positivo para o HIV passou a ter a representação da morte anunciada, de difícil manejo tanto para o profissional de saúde, enquanto portador da má notícia, quanto para quem a recebia, marcando profundamente a história da epidemia em seu período inicial.

Atualmente, a epidemia de AIDS apresenta profundas alterações em seu perfil epidemiológico, gerando mudanças no cuidado prestado aos distintos grupos acometidos pela síndrome $e^{23,24}$, influenciados tanto pela disponibilização do tratamento antirretroviral, quanto pelo reconhecimento que a vulnerabilidade a doença não se restringe apenas a grupos específicos, mas a população em geral ${ }^{25}$. Porém, percebe-se a necessidade de ações integradas junto às políticas públicas na intenção de se obter maior responsabilidade e comprometimento com as ações preventivas e de controle da infecção pelo HIV ${ }^{26,27}$. Nesse cenário, o enfermeiro é um profissional que tem muito a contribuir, seja no seu papel assistencial, quanto no delineamento de políticas que possam responder a epidemia com maior efetividade.

\section{Conclusão}

Ao descrever o contexto em que surgiram as primeiras ações em resposta à epidemia da AIDS, em Florianópolis, observamos que, a partir da ocorrência dos primeiros casos na cidade, a estruturação da assistência em AIDS foi assumida pelo Hospital Nereu Ramos, que supriu a baixa capacidade de resposta do município nos serviços e políticas de saúde. A conjuntura política da época contribuiu não apenas para a assistência aos pacientes com HIV/AIDS, visto que seu espaço institucional foi o locus das duas primeiras organizações não governamentais do município e Estado de Santa Catarina.

A participação do município nas ações voltadas para a AIDS, durante a década de 1980 , foi pautada pela iniciativa de alguns profissionais de saúde de forma não sistematizada, que se preocuparam em esclarecer a população a respeito da nova epidemia, utilizando a informação como principal recurso. Este quadro começa a sofrer transformações a partir de 1990, quando o SUS começa a ser gradativamente implantado e a municipalização da saúde começa a avançar.

Diante desse cenário inicial, destaca-se a atuação dos primeiros profissionais de saúde envolvidos com a epidemia da AIDS em Florianópolis, que entenderam que além de adaptar e estruturar os serviços para acolher a população, tinham que desenvolver estratégias para lidar com questões bastante complexas, que expressavam a situação de caos produzida pela doença, por seus estigmas e por sua íntima relação com a morte.

Percebeu-se o relevante trabalho de profissionais de saúde, em especial de enfermeiras que, com suas ações empreendedoras, atuaram em diversos cenários nesse município, seja na assistência a essa população, na estruturação dos primeiros serviços ou na participação da criação das primeiras organizações não governamentais, visando contribuir para a defesa dos direitos das pessoas que vivem com HIV/AIDS.

As limitações deste estudo encontram-se nos poucos documentos históricos identificados em relação à temática, o que indica que tanto profissionais, quanto as próprias instituições, carecem de maior espírito de preservação de sua própria história e dos acontecimentos marcantes, correndo o risco de caírem no esquecimento, conforme o distanciamento do próprio tempo. 


\section{REFERÊNCIAS}

1.Santos GGC. AIDS, Política e Sexualidade: refletindo sobre as respostas governamentais à AIDS na África do Sul e no Brasil. Physis, 2009; 19 (2): 283-300. [citado em 06 jun 2014] Disponível em http://www. scielo.br/scielo.php?script $=$ sci_arttext $\&$ pid $=$ S0103 $73312009000200003 \& \operatorname{lng}=\mathrm{pt} \bar{E}^{-} \mathrm{nrm}=$ iso

2.Mendonça PME, Alves MA, Campos LC. Empreendedorismo institucional na emergência do campo de políticas públicas em HIV/AIDS no Brasil. RAE electron, 2010; 9 (1): 0-0. . [citado em 04 jun 2014] Disponível em: http:// www.scielo.br/scielo.php?script $=$ sci_arttext\&pid $=$ S1676$56482010000100007 \& \operatorname{lng}=$ pt\&nrm $=$ iso

3.Teixeira PR. Políticas públicas em AIDS. In: Parker $\mathrm{R}$, organizadores. Políticas, instituições e AIDS: enfrentando a epidemia no Brasil. Rio de Janeiro: Jorge Zahar - ABIA; 1997. p. 43-68.

4.Gauri V, Lieberman E. AIDS and the State: The politics of government responses to the epidemic in Brazil and South Africa. In: Annual meetings of the american political science association. Chicago; 2004. [cited in 2014 Sep 10] Disposable in: http://cyber.law.harvard. edu/blogs/gems/politicshiv/liebermanpaper.pdf

5.Secretaria de Estado da Saúde (SC). Diretoria de Vigilância Epidemiológica. O perfil epidemiológico da AIDS. Florianópolis(SC): DIOESC; 2010.

6.Maliska ICA. A implantação das políticas públicas de saúde em AIDS no município de Florianópolis-SC: um estudo do período de 1986 a 2010 [tese de doutorado]. Florianópolis (SC): Universidade Federal de Santa Catarina; 2012.

7.Parker R, organizador. Políticas, instituições e AIDS: enfrentando a epidemia no Brasil. Rio de Janeiro: Jorge Zahar-ABIA; 1997.

8.Secretaria de Estado da Saúde (SC). Diretoria de Vigilância Epidemiológica. Banco de Dados do SINANW - Sistema Nacional de Agravos de Notificação. Casos de AIDS em adultos e crianças segundo categoria de exposição e ano de diagnóstico, município de Florianópolis, 1986-2011. Florianópolis (SC): SES-SC; 2011.

9.Le Goff JA. A história nova. 2 ${ }^{\mathrm{a}}$ ed. São Paulo: Martins Fontes; 1993.

10.Alberti V. Manual de história oral. 3a ed. Rio de Janeiro: FGV; 2005.

11.Bardin L. Análise de conteúdo. Lisboa (Pt): Edições 70; 2004.

12.Miranda AFB. História da AIDS em Santa Catarina: características de uma epidemia [dissertação de mestrado]. Florianopolis(SC): Universidade Federal de Santa Catarina; 2003.

13. Westrupp MHB. Práticas sexuais de mulheres de parceiros infectados pelo HIV: contribuições acerca da cadeia epidemiológica de transmissão do HIV/AIDS [tese de doutorado]. Florianopolis(SC): Universidade Federal de Santa Catarina; 1997.
14.Secretaria de Estado da Saúde (SC). Diretoria de Vigilância Epidemiológica. Gerência de Vigilância das DST/HIV/AIDS. 25 anos da epidemia de AIDS: uma história de lutas, avanços, desafios e conquistas. [citado em 26 ago 2014] Disponível em: http://www.dive.sc.gov. br/conteudos/gerencia_dst_AIDS/noticias/2009/Historico_25_anos_de_Epidemia.pdf.

15.Ministério dā Saúde (Br). Secretaria de Assistência a Saúde. Portaria no 70, de 17 de julho de 1995. Define hospital autorizado para cobrança dos procedimentos tratamentos da AIDS -hospital/dia. [citado em 20 jun 2014] Disponível em: http://dev-sus20anos.datasus.gov. br/SUS20ANOS/index.php?area $=010304$.

16.Ata da Assembléia Geral Extraordinária de Formação do Grupo de Apoio à Prevenção da AIDS de Florianópolis - GAPA. Florianópolis (SC): GAPA; 1987.

17.Maliska ICA, Padilha MI, Meirelles BS, Koller EMP, Andrade SR. A AIDS em Santa Catarina, Brasil: um histórico dos 25 anos de epidemia. Cad Saúde Coletiva. 2011; 19: 147-56.

18.Nascimento DR. As pestes do século XX: Tuberculose e AIDS no Brasil, uma história comparada. Rio de Janeiro: Fiocruz; 2005.

19.Galvão J. AIDS no Brasil: agenda de construção de uma epidemia. Rio de Janeiro: ABIA; 2000.

20.Mann J, Tarantola DJM, Netter TW. A AIDS no mundo. Rio de Janeiro: ABIA/IMS, UERJ; 1993.

21.Fonseca AF. Políticas de HIV/AIDS no Sistema Único de Saúde: uma busca pela integralidade da atenção. In: Escola Politécnica de Saúde Joaquim Venâncio. Textos de apoio em políticas de saúde. Rio de Janeiro: Fiocruz; 2005.

22. França MSJ. Política, direitos humanos e AIDS: uma conversa com Paulo Roberto Teixeira. Interface (Botucatu). 2008; 12: 919-26.

23.Gomes AMT, Barbosa BFS, Oliveira DC, Wolter RMCP, Silva MVG. As representações sociais de enfermeiros sobre a criança soropositiva para HIV: interface com o cuidar. Rev enferm UERJ. 2011; 19:14-9.

24.Lima DJM, Araújo ACM, Mendes IC, Oriá MOB, Aquino OS, Pinheiro AKB. Completude e consistência dos dados de gestantes HIV positivas notificadas. Rev enferm UERJ. 2014; 22: 321-6.

25.Parkhurst JO. Structural approaches for prevention of sexually transmitted HIV in general populations: definitions and an operational approach. Journal of the International AIDS Society 2014; 17:19052 [cited in 2014 Oct 15] Disposable in: http://www.jiasociety.org/ index.php/jias/article/view/19052

26.Galvão MTG, Gouveia AS, Carvalho CML, Costa E, Freitas JG, Lima ICV. Temáticas produzidas por portadores de HIV/AIDS em grupo de autoajuda. Rev enferm UERJ. 2011; 19:299-304.

27.Marta CB, Leite JL, Peregrino AAF, Schutz V, Francisco MTR, Magnago C. Custos da adesão ao tratamento da Síndrome da Imunodeficiência Adquirida: estudo transversal. Rev enferm UERJ. 2014; 22:193-9. 